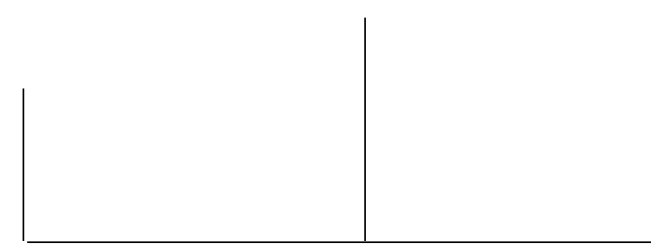

Rev. Latinoam. Psicopat. Fund., VII, 1, 20-39

\title{
A criação do campo psicanalítico na instituição
}

Sueli Pinto Minatti

\begin{abstract}
Este texto surge da tentativa de definir atendimentos feitos dentro de uma instituição, a partir da proposta de um trabalho psicanalítico. A análise dessa situação faz-se por um recorte e uma montagem, um recurso artificial, levando em consideração o espaço institucional, com sua história e finalidade, como espaço de acolhimento. Como personagens centrais estão os habitantes da instituição, cujo foco é o sujeito, distinto de pessoa. Como terceiro elemento, a psicanalista, cuja presença tem possibilitado o surgimento de um campo, aqui considerado. No encontro entre a instituição e seus componentes e a psicanalista, vai-se delineando uma dinâmica em que há possibilidade de aparecimento do sujeito em meio às pessoas, nas relações. Essa trajetória fala de possibilidades ou impossibilidades como o campo da pessoa. Fala também de possibilidades e impossibilidades como o campo do sujeito.
\end{abstract}

Palavras-chave: Psicanálise, instituição, sujeito, transferência 

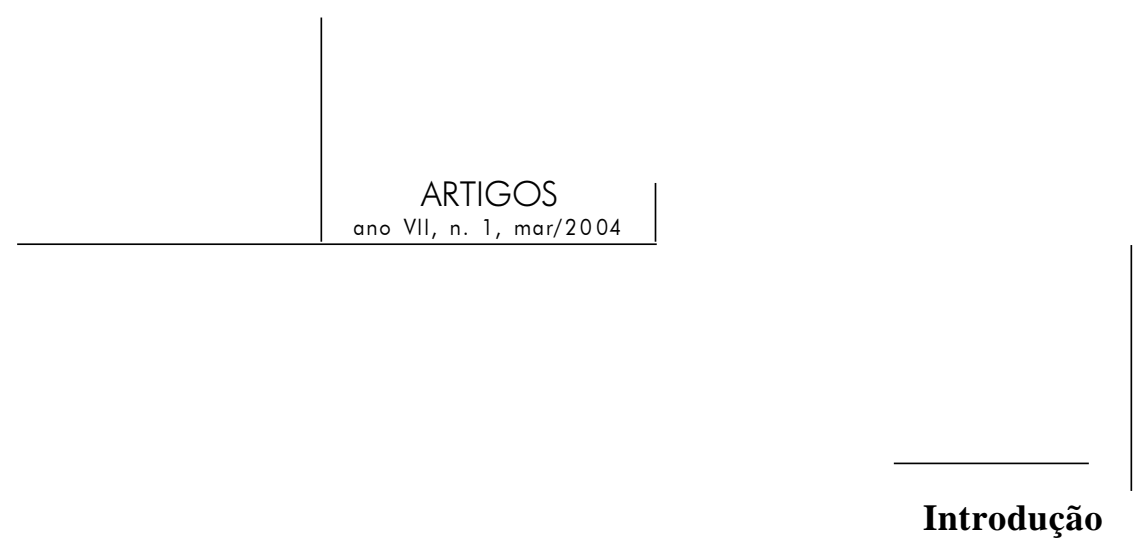

Este texto visa trazer ao âmbito da escrita uma experiência a partir de algo que vai sendo vivido num certo contexto, num certo período de tempo. $\mathrm{O}$ que é vivido, pathos, pode ser apenas um padecimento, podendo levar ao esquecimento e à morte. Pode também movimentar-se, tornando-se uma experiência, se for testemunhado por alguém que está fora, e que, nessa condição, traz o poder da cura (Berlinck, 2000).

A experiência aqui relatada surge de uma vivência de cinco anos de atendimento numa instituição. No trajeto entre a vivência e a experiência, o que chamou atenção foi uma especificidade do trabalho que aí se dá, diversa da que acontece num setting psicanalítico de consultório, desde a forma em que as queixas e os pedidos aparecem até a quem as demandas são dirigidas. Também os locais onde são feitas as entrevistas, seu tempo de duração, bem como as interrupções e os intervalos entre elas compõem essa ${ }^{1}$ especificidade, que fez surgir esta pesquisa como uma tentativa de investigação e definição do trabalho psicanalítico que aí acontece.

Essa instituição acolhe pessoas, principalmente crianças, com doenças graves, principalmente câncer, que vêm de vários pontos do país e lá se hospedam durante o período do tratamento.

O eixo teórico escolhido para referendar e situar o material clínico encontrado e conduzi-lo a partir dessa problemática é a transferência. A forma de organizar esse material faz-se em referência a alguns elementos que se relacionam. Parte-se de três elementos relacionais: a instituição, o sujeito emergente dentre as pessoas que habitam a instituição e a psicanalista como representante do campo teórico nesse contexto. Há, ademais, o pathos, como o cerne da constituição da instituição/sujeito, e a transferência, como o conceito psicanalítico, meio de aproximar as possibilidades das impossibilidades.

Dos três elementos relacionais, um deles, a instituição, é representada pelo propósito com que se estabelece e o modo de funcionamento a partir desse(s)

1. As formas de encaminhamento aos atendimentos, assim como as formas de atendimento, foram tratadas em outro texto: Minatti, Sueli Pinto, A transferência como via de reflexão para atendimento numa instituição, 2002. 


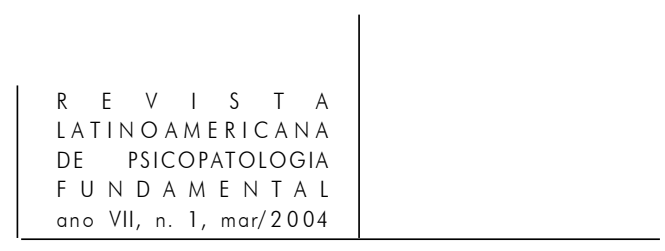

propósito(s). Essa instituição nasce num intervalo entre um lugar de moradia e um lugar de tratamento. O lugar de moradia é a residência de famílias de poucos recursos financeiros e culturais, principalmente nas regiões norte e nordeste do Brasil, onde e quando em um dos seus componentes aparece uma doença grave. O lugar de tratamento passa a ser um hospital em São Paulo, público na maioria, mas também privado, para onde essas famílias são encaminhadas como último recurso diante desse grave acometimento. Entre os dois, a instituição casa de apoio, como é chamada, onde o doente e um acompanhante podem hospedar-se durante o período de tratamento.

O segundo elemento considerado é o sujeito representado pelas pessoas da instituição. Pessoas, no sentido de corpos, com nomes, famílias, endereços. Essas pessoas tendem a adaptar-se às normas determinadas pela instituição, acolhedora e provedora. Algumas dessas normas são verbalizadas já ao primeiro contato; outras, inferidas ao longo da estada. Sujeito, no sentido de seres falantes assujeitados à linguagem estabelecida, ao mesmo tempo que livres na escolha e composição dos elementos dessa linguagem de forma a compor uma fala localizadora de seu desejo.

Como terceiro elemento possibilitador desse entrelaçamento, está a psicanálise, representada, nesse contexto, pela psicanalista presente na instituição e, sobretudo, pela teoria psicanalítica, que possibilita um movimento dialético entre o fato e o relato do fato. Dito de outra forma, na busca da verdade de cada sujeito em lugar da definição da realidade (Faria, 1998). A via dessa investigação é feita pela fala, forma de ação que instaura a dimensão da verdade (Valas, 2001). Podem-se acompanhar diferentes formas de aproximações e recuos do sujeito e, a partir desses movimentos, diferentes lugares são atribuídos à psicanalista. Só para situar alguns, há o lugar de quem pode falar e de quem pode escutar, de confidente, de onipotente, de saber, de onde se pode mostrar seu não saber, de precipitação, de espera, de dúvida, de controle, de desejos não manifestos e de desejos anunciados. Há, ainda, a enunciação da possibilidade de outras formas de funcionamento que talvez possam ser ensaiadas, ou que talvez já o foram e que, bem ou malsucedidas, trazem questionamentos sobre sua validade.

Esses sujeitos, em sua maioria, não procuraram um atendimento, não tinham uma queixa ou um pedido endereçado a um psicanalista. Mas o psicanalista estava lá e foi possível estabelecer alguma forma de laço e, por meio dele, falas que, em alguns casos, podem ser lidas como queixa ou como pedido.

Esta nova espacialidade, uma criação teórica como forma de tentar passar ao âmbito do relato da experiência algo vivido, irremediavelmente apresenta os personagens institucionais em confronto ou relação, como veremos adiante. Nesse confronto aparecem soluções possíveis ou impossíveis como formas excludentes, no âmbito de pessoa. Ou as pessoas se adaptam às normas institucionais ou são 


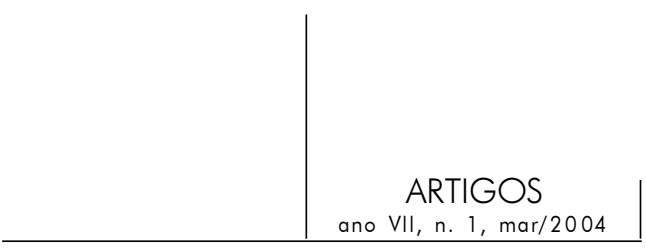

excluídas desse espaço. Também aparecem soluções possíveis $e$ impossíveis como formas relacionais, em que a negociação e a investigação possibilitam formas criativas e singulares de convívio.

A exploração dessa superfície faz-se a partir da definição e/ou situação de alguns temas: o sujeito, a instituição, pathos e a psicanalista, tendo como ponto de partida o conceito de transferência.

\section{O sujeito}

A originalidade da obra freudiana, se a considerarmos a partir do discurso médico, deu-se pela introdução do sujeito. Nos hospitais, diante das histéricas, consideradas doentes pela medicina, a consideração de Freud não se deu pela oposição à doença, o que teria sido um rebate no mesmo campo de poder. Sua grande construção deu-se num outro campo. Ele disse tratar-se de outra coisa; essa coisa formulada por ele como o lugar do inconsciente como substantivo. Ao definir essa substância, Freud deu a ela um lugar. O sujeito que aparece com Freud emerge de um campo já existente, o da filosofia, e passa ao campo denominado psicanálise, cuja topologia vai sendo construída à medida que vai sendo definida.

Assim, ele é sempre considerado, desde sua lógica única, dentro de uma lógica formal constituinte de uma instituição, seja ela a família, o exército, a igreja, a civilização; a última, contendo as demais, lugar de origem da lógica dominante: a linguagem.

Ao colocar como tema a sociedade em seu contexto mais amplo, Freud trata da constituição do sujeito pelo conflito entre sua vida pulsional e o sacrifício da pulsão ${ }^{2}$ a favor do social. ${ }^{3} \mathrm{O}$ sujeito, para Freud, é em relação ao outro. O conceito de outro é retomado em Lacan como outro, semelhante, e Outro, o lugar da linguagem, o lugar do simbólico, que enquadra os fenômenos imaginários oriundos do narcisismo (Quinet, 2000).

2. A pulsão "constitui o ponto-limite em que se percebe a especificidade do desejo do sujeito (...) ela permite construir uma verdadeira topologia dos bordos, finalmente surgindo como um dos principais modos teóricos de acesso ao campo do real, termo da estrutura lacaniana que designa aquilo que é impossível para o sujeito" (Chemama, 1995).

3. Refiro-me especialmente aos textos: Moral sexual civilizada e doença nervosa moderna (1908), Totem e tabu (1912) Reflexões para os tempos de guerra e morte (1915), Psicologia do grupo e a análise do ego (1921) e Mal-estar na civilização (1930). 


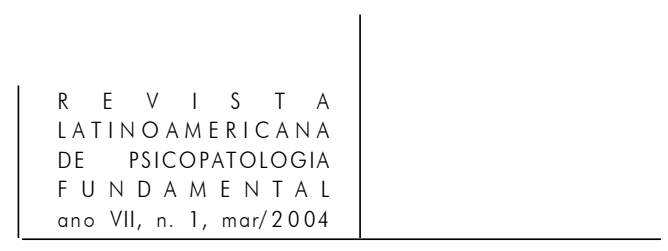

Desse sujeito podemos apreender a singularidade em suas tentativas de assemelhar-se ou diferenciar-se do outro, diante e a partir do Outro. Esse sujeito aparece na escolha e utilização da fala que o coloca nessa relação.

Considera-se aqui, na referência ao sujeito depois de Freud, segundo releitura de Lacan, os três registros definidos como: real, simbólico e imaginário. De forma bastante simplificada, para continuar a análise desse contexto, pode-se dizer do imaginário como o campo do possível, o real como o campo do impossível e o simbólico como tentativas de entrelaçamento do possível e o impossível. Esse mundo imaginário, onde transita a possibilidade, é o que permite, com o aparecimento do sujeito, o enfrentamento ao impossível, podendo, talvez, articular-se a ele.

$\mathrm{O}$ conceito de sujeito, inaugurado em Freud, tem sido retomado muitas vezes. Sujeito, para Fink, "não é algo ou alguém que tenha algum tipo de existência permanente, só aparece quando uma ocasião favorável se apresenta. (...) O que é mais notável a respeito do sujeito freudiano é que ele desponta apenas para desaparecer quase instantaneamente" (1998, p. 62 e 64). Esse sujeito fugaz apresenta-se através de seu sintoma, ${ }^{4}$ sua forma singular de expressar o conflito entre sua vida pulsional, traço de sua singularidade, e o contexto relacional. ${ }^{5}$ Além do sintoma, o analista conta, para a expressão do sujeito, com as demais formações do inconsciente: atos falhos, chistes e sonhos.

Esse sujeito aparece em meio às pessoas, componentes do meio social. Pessoas "atadas aos lugares que ocupam numa rede estreita e densa de relações e histórias coletivas e submetidos a uma 'ética da excelência' - em que cada um deve se dedicar às funções e às tarefas que lhes são destinadas para superarse no seu exercício..." (Figueiredo, 1995, p. 37). Esse meio tenta ser ordenado segundo uma ordem comum em que o registro imaginário é seu maior propulsor.

Ao mesmo tempo o sujeito é arbitrário, a partir de seu trajeto pulsional, em relação a esse meio. "Um sujeito não é um resultado - como tampouco é uma origem. Ele é o estatuto local do procedimento, uma configuração excedentária da situação" (Badiou, 1988, p. 309). Esse sujeito, portanto, é levado em consideração na organização do social. O social o leva em consideração quando tenta ultrapassá-lo e também o ignora, pela própria ultrapassagem. Pode-se dizer que as normas sociais são estabelecidas a favor, ou apesar, dos sujeitos que as constituem.

4. "Fenômeno subjetivo que constitui, para a psicanálise, não o sinal de uma doença, mas a expressão de um conflito inconsciente" (Chemama, 1995).

5. Este o contexto da pessoa com suas relações, seus nomes, sua história (Figueiredo, 1995). 


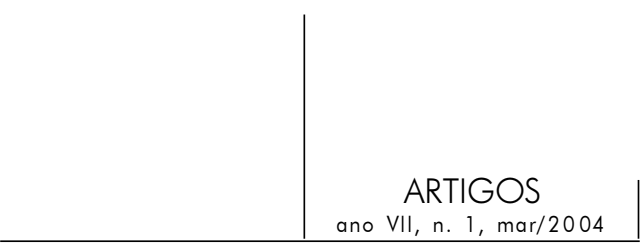

Na constituição fundante do sujeito, a alienação é fundamental e é condição da separação. Posteriormente, ele apresenta novas e constantes tentativas de alienação e, nessas tentativas, ele demanda. Na demanda, portanto, está o sujeito alienado da via do desejo que o constitui, mas que não é reconhecido por ele. Atender à demanda pode significar permitir a alienação. Escutá-la e remetê-la ao seu emissor pode significar o reconhecimento do sujeito pelo reconhecimento do seu desejo.

O aparecimento do sujeito num meio social em que se tenta, pela legalidade institucional, a invariabilidade, pode provocar desordenações. Essas desordenações surgem na casa de apoio. O sujeito, com ordenação própria, pode aparecer de forma estranha - no sentido de não reconhecido - tendendo a retrair-se sem reconhecer-se.

Um outro destino a esse sujeito pode acontecer a partir da escuta. Ao ser escutado em sua forma singular e também criativa, e à medida que essa escuta permite uma construção de si próprio a partir do objeto a que ele se refere, ele pode encontrar uma localização possível.

Tentando situar o material clínico, origem deste trabalho, e a organização social onde ele aparece como forma de atentar aos seus movimentos, tenta-se definir a instituição onde acontecem os atendimentos.

\section{A instituição}

Trata-se de uma casa com mais ou menos oito dormitórios, ${ }^{6}$ localizada num condomínio residencial, num município próximo a São Paulo. Hospeda entre 20 e 50 pessoas, famílias com domicílio longe ${ }^{7}$ de São Paulo, quando um dos seus elementos necessita de tratamento prolongado. Embora seu nome seja "Casa de Apoio à Criança com Câncer", não necessariamente o elemento familiar acolhido por essa instituição tem câncer, como nem sempre trata-se de criança. A instituição acolhe pessoas com doenças graves; preferencialmente crianças.

Além de atender assistencialmente as pessoas que hospeda, essa casa contrata e/ou assiste famílias que se deslocaram a São Paulo no período de tratamento, e que aqui permaneceram, morando próximo à instituição. Para essas

6. As reformas para ampliação da casa são constantes. Os dormitórios são separados entre masculinos e femininos e são compostos de beliches e alguns armários.

7. Passaram em atendimento algumas pessoas com domicílio no interior do Estado de São Paulo, mas essas são exceção. Na regra estão pessoas vindas de distância superior a $1.000 \mathrm{~km}$, preferencialmente do Norte e Nordeste; grande parte de Porto Velho e arredores. 


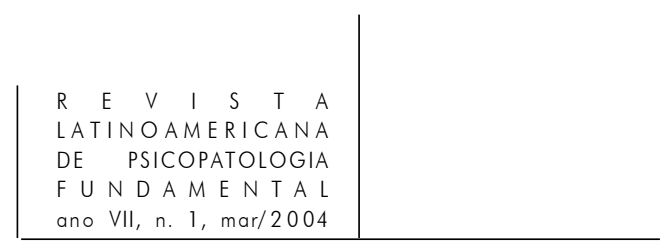

famílias a instituição passa a ser um referencial de endereço e de asseguramento. A transferência de moradia para São Paulo ocorre, em geral, por possibilidades de emprego e ascensão econômica, sobretudo quando, durante o tratamento prolongado, os demais elementos familiares também se deslocam para São Paulo. Muitas vezes essa decisão permanece mesmo após o falecimento daquele que estava em tratamento. A maioria dessas pessoas presta serviços à instituição: nas construções, na arrecadação e distribuição de doações, em outros serviços de estrutura e manutenção.

Os habitantes da instituição são compostos por famílias vindas a São Paulo em busca de tratamento médico a um de seus membros. Encontram nessa instituição hospedagem durante o período necessário ao tratamento, variável entre alguns dias e alguns anos. O contato com a instituição é feito pelo hospital onde está sendo realizado seu tratamento, em geral, quando se constata a falta de recursos necessários à sua estada durante o período de tratamento. Também podem ser encaminhados por assistente social desde sua cidade de origem. A viagem a São Paulo, geralmente feita às pressas, sem nenhum planejamento ou recursos financeiros, costuma ser um dos primeiros desafios para essas pessoas, que são, na sua totalidade, de nível econômico baixo e pouca cultura formal. Várias delas perdem o emprego ao virem para cá, e muitas mulheres perdem o companheiro.

A justificativa para a fundação da instituição é apresentada como o atendimento do desejo de uma pessoa morta pelo câncer - aquela que dá o nome à instituição. Durante seu tratamento, carecendo de uma casa para morar aqui em São Paulo, ela idealizava um espaço de acolhimento de outras pessoas que viessem a precisar de tratamento. Essa justificativa tenta ser constantemente reafirmada, assim como permeia as normas institucionais. Estas, no entanto, vão sendo modificadas na medida que o espaço institucional e a organização nesse espaço vai se modificando.

A instituição situa-se, no decorrer da pesquisa, centrada pelo poder fundante, tendo, no entanto, o poder de decisão e direcionamento localizado clara e hierarquicamente pela dirigente e pela coordenadora de serviços, em geral uma mulher de mais tempo de convívio na casa, considerada pessoa de confiança da dirigente, de onde partem os comandos operacionais, na ausência desta. O objetivo da instituição é fazer o bem, princípio da moral, estabelecido pela justificativa da fundação e mantido hierarquicamente. Há normas e proibições sobre: horários - de dormir, acordar, assistir televisão -, relacionamentos amorosos, saídas a passeio, formas de vestuário e distribuição de tarefas, formas de executar os serviços e organizar a casa, distribuição de material de consumo e doações. Algumas destas normas ou proibições são ditas, outras são transmitidas pelo silêncio e vão sendo inferidas, dando margem a confusão. 


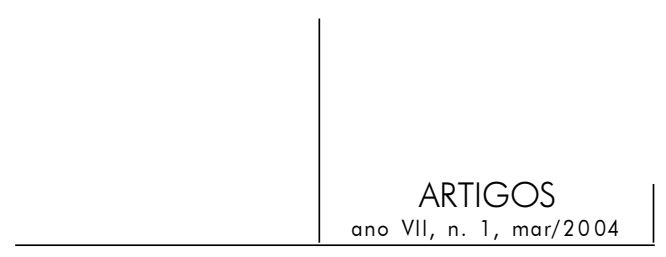

Os dispositivos institucionais são utilizados no sentido de obediência a essas normas: demissões, contratos, ameaças, privilégios e concessões entram no jogo institucional.

O abrigo oferecido pela instituição aparece como importante ao âmbito de pessoa, uma vez que lhe oferece referência de endereço e direcionamento num contexto novo e precariamente compreendido. Da mesma forma aparecem como importantes a medicina e os médicos, conferindo a essas pessoas igualdade imaginária, em meio a tantas disparidades. "A medicina realiza em princípio a igualdade na doença. Para aceder à igualdade, outrora bastava estar morto. É suficiente agora estar doente" (Clavreul, 1983, p. 32). Assim, costumam referirse aos médicos pelo primeiro nome e falar deles com bastante familiaridade, ou ainda gabar-se da forma como se pode transitar entre os profissionais da saúde com desenvoltura anteriormente desconhecida.

Ao mesmo tempo que a instituição torna-se uma proteção ao sujeito, assegurando seus vínculos (Kaës, 1989), ela inibe o aparecimento da singularidade, tornando-se também o propiciador de seu sofrimento e a referência por onde a singularidade do sujeito pode despontar. "O universal exige (...) a existência da exceção" (Prates, 2001, p. 84). Pessoa e instituição conformamse. As regras tentam conter o sujeito e, diante das normas estabelecidas na instituição, procurando ultrapassá-las ou obedecê-las, o sujeito insiste algumas vezes com sofreguidão, outras vezes de forma fugaz.

Pathos

Seja qual for a forma dessa insistência e sejam quais forem os caminhos que percorra, ela pode ser entendida como sofrimento, pathos. "Além de sofrimento, de pathos deriva-se, também, as palavras 'paixão' e 'passividade'. (...) quando pathos acontece, algo da ordem do excesso, da desmesura se põe em marcha sem que o eu possa se assenhorear desse acontecimento, a não ser como paciente, como ator" (Berlinck, 2000, p. 18).

Nessa instituição o sofrimento tem um lugar privilegiado a partir de uma certa definição. O primeiro e mais evidente sofrimento, estampado nos letreiros da instituição, é a doença grave que aparece numa forma bastante contundente: câncer. Essa via dá ao sofrimento a marca do corpo físico e da emergência. São esses os referenciais do sofrimento; qualquer outro é colocado em desconsideração. A instituição coloca-se como aliada na luta contra a doença e tem como propósito aplacar o sofrimento; esse é seu bem, que vai se desdobrando em outros bens assistenciais, disponibilizados por critérios institucionais centralizadores. 


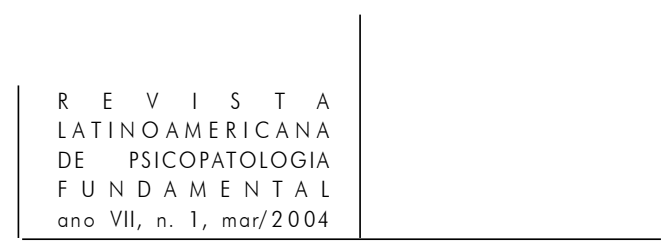

Privilegia-se o trabalho voluntário e as doações no sentido de silenciar o sofrimento. Tardes de orações acentuam o poder divino capaz de solucionar qualquer mal, sustentando o apelo ao "Médico dos médicos". Freqüentes passeios e eventos são proporcionados por serviços voluntários, além de festas e doações de brinquedos, roupas e outros objetos de consumo. As pessoas acolhidas pela instituição passam a ter acesso a um padrão financeiro e social até então inacessível, seja pelo mobiliário da casa, tipo de alimentação, vestimentas e brinquedos recebidos como doação em grande quantidade ${ }^{8}$ Uma mãe refere-se a toda essa mudança, incluindo a viagem de avião, os constantes e diferentes trajetos aos hospitais e as palavras médicas, antes desconhecidas e agora no mínimo pronunciáveis: "Se tudo isso não tivesse acontecido, eu nunca teria saído da minha cidade. Eu era muito limitada". Limites foram transpostos. Que limites são esses?

Para as pessoas, o propósito institucional pode parecer claro. Também pode parecer claro, por vezes, o que é endereçado ao médico. No entanto, tanto num como noutro endereçamento, há algo que resta e aparece como queixa sobre falta de atenção ou atendimento inadequado. O limite do que se espera da instituição, dos médicos e "d'Aquele lá em cima", dispostos, freqüentemente, hierarquicamente, oscila entre o milagre e a confusão, uma vez que, ao chegarem a São Paulo, consideram ter possibilidade de acesso ao ponto mais alto no que diz respeito aos recursos recebidos.

Pode-se ainda dizer que a linguagem põe o indivíduo dentro do engano em que o engano maior é sua eternidade. Embora ele saiba da morte, vive como se não soubesse, deixando essa questão para depois. Quando se surpreende não totalmente conformado, pode ir em busca do desvelamento. Esse desvelamento pode ser evitado socialmente por comportar o risco de perder a forma. Lançandose à aventura de desvelamentos, procura asseguramentos.

No entanto, como acontece com freqüência diante da doença grave, quando esse desvelamento torna-se um desengano, um grande furo aparece, não encontrando muitas vezes bordas simbólicas - ou encontrando apenas bordas frágeis - que possam sustentá-lo. O relato, no encontro psicanalítico, é uma forma de desvelamento em que o asseguramento está apoiado pela transferência.

"Não tem palavra", foi o que disse sobre esse desvelamento um garoto de 14 anos. Antes que ele chegasse a mim, foi sendo anunciado por vários habitantes da casa. Os pedidos de atendimento se faziam por seu mutismo desde o desengano

8. As doações em roupas e brinquedos geram grandes volumes que se tornam, geralmente, problemas de envio aos demais membros da família, em sua cidade de origem. 


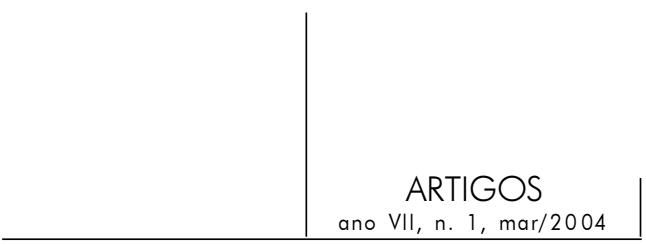

médico. Tem vindo regularmente relatando filmes - começou pelo Matrix - que lhe possibilitam "trocar" nossos corpos para tentar falar. "Eu sou você e você sou eu. Quando eu entro em você, se eu morrer, é você que morre.”

O corpo é esse grande velamento que a palavra vai cobrindo e descobrindo. Falar sobre a troca de corpos é falar de outras possibilidades do corpo que o desvelamento médico, imposto como veredicto, põe a descoberto numa crueza muito difícil de ser suportada.

Desde março de 1955, com a leitura do sonho da injeção de Irma, sonho relatado por Freud, Lacan formula que deparar-se com o real - as placas acinzentadas da garganta - é ficar mudo e imóvel diante do horror. No sonho, solução vem pela fórmula - o simbólico. O simbólico da fala que interroga e leva a uma investigação é uma forma de contornar esse real. O imaginário pode tamponá-lo unificando-o numa imagem ou crença.

Nesta instituição a forma mais constante do real é o câncer e as outras doenças graves que irrompem trazendo uma divisão diferente daquela em que há o elo articulatório onde se localiza o sujeito. Essa divisão deixa um silêncio mortífero.

\section{A psicanalista}

A chegada da psicanalista à instituição, e sua intenção, confere o estabelecimento de um campo que vai no ritmo e forma do sujeito, a partir de então considerado, o que marca uma diferença.

O que é endereçado à psicanalista é o que circunda e/ou atravessa a doença e o doente. Seja o que pode ser dito como não doente, seja um ideal, seja a fraqueza, assim considerados, por exemplo, o choro ou o pedido de ajuda, seja o proibido pela instituição. O que se ensaia e se constrói faz parte do próprio trajeto da psicanalista na instituição, que vai se estabelecendo a partir desses movimentos subjetivos, conformando um campo desde essa perspectiva. À medida que o lugar da psicanalista vai se constituindo, o campo psicanalítico também se constitui, com o sujeito como foco. A suposição de um psicanalista, de um lado, corresponde, de alguma forma, à aposta do sujeito, de outro; esse é o interjogo dentro desse campo.

No espaço institucional, as especulações imaginativas, com tendências unificadoras, têm sua tônica. Vão, no entanto, tomando configurações especiais e particulares, desde o aparecimento de demandas alienantes a suposições de um saber na psicanalista, propiciadores de transferência simbólica, via propícia ao saber sobre si. Essas configurações singulares que podem explicitar desconforto 


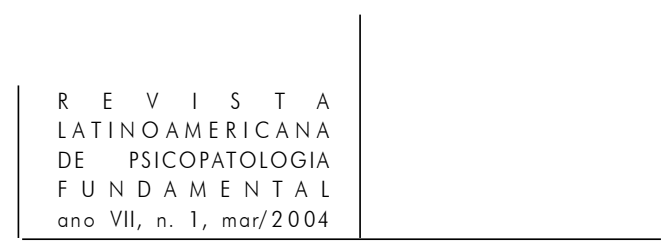

tendem a ser aplainadas dentro das normas institucionais. Encontram, no entanto, outro destino diante dessa topografia que aí se engendra.

Desses encontros, seus efeitos e suas formas são inesperados. Algumas vezes, o efeito é meramente terapêutico - um desabafo, como costumam dizer - aliviando ou suprimindo sintomas, ou, ainda, situando as pessoas em seu meio. A maior parte dos encontros são esporádicos; no entanto, alguns são constantes - no ritmo institucional -; refiro-me àqueles que comparecem às entrevistas sempre que se instalam na instituição, o que pode significar semanas ou meses, com intervalos de outras tantas semanas ou meses. Em alguns desses casos, o endereço da psicanalista aparece como possível asseguramento. Uma queixa pode ser formulada, ou ainda, caso não freqüente, uma demanda pode ser construída. Demanda é entendida como pedido elaborado a partir da existência da falta, endereçado a um outro como representante do Outro, que supostamente a suportaria.

Ao chegar à instituição me foi sendo dito, nos corredores, que eu deveria conversar com N. Ela me esperava. "Dra., não aceito que me contrariem. (...) Vomitei 29 vezes". N. procurou-me na semana seguinte com a pergunta "Por que eu não sou como as outras?". Este era seu último dia na instituição. Eu a vi dois anos depois. "Dra., lembra de mim? Eu nunca esqueci da senhora. Agora vim trazer meu outro filho." Escreveu-me depois dizendo que tinha procurado uma psicóloga em sua cidade, mas não gostava de falar de "suas coisas" em grupo. Minha carta-resposta não chegou até ela (endereço desconhecido).

Esse fragmento do atendimento feito a $\mathrm{N}$. ilustra o que vinha sendo anunciado acima como formas de atendimento, assim como seus efeitos. Além disso, há, também, uma especificidade quanto aos locais em que os atendimentos são feitos. Dentro da organização institucional, diferentes espaços já foram destinados à psicanalista. Houve momentos de atendimentos feitos nos corredores, à beira do tanque de lavar roupa, da pia de lavar louça, do fogão, à beira da cama. Houve tempo em que havia uma sala para atendimento. Houve tempo em que os atendimentos eram feitos fora da instituição, na escola. Esses movimentos, quando designados pela administração, falam do imaginário e da suposição que a administração institucional faz do que seja o lugar da psicanalista. Assim como falam de sua relação com outras instituições, num elo institucional. Por exemplo, a volta dos atendimentos dentro da instituição, depois desse tempo em que aconteciam na escola, deu-se logo depois de uma queixa de um dos habitantes da casa a uma assistente social, num hospital onde seu filho fazia tratamento, de que "a instituição não tinha quem a ouvisse".

Enquanto transita por todos esses espaços, que indicam lugares, ocupa o título de psicanalista - assim se nomeou quando lhe foi perguntado, depois do seu nome, o que fazia. Esse, que aparece como um título, pode configurar-se 


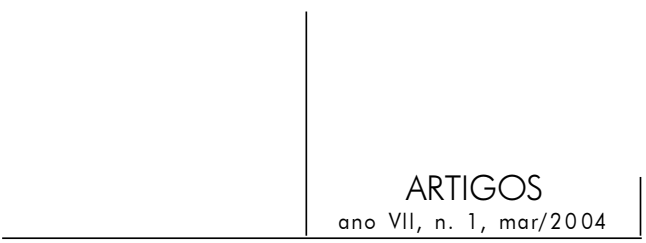

também como enigma, cujos significados vão sendo ensaiados. Os ensaios são algumas vezes explícitos: “A senhora é o que mesmo?”, "O que se fala aqui?", "Eu pensei que a senhora fosse ensinar alguma coisa". Outras vezes, as tentativas a essa nomeação são feitas em função de como essa população movimenta-se diante dessa presença. Esses movimentos vão desde encaminhamentos a algo que parece não ter lugar dentro da instituição, à rejeição a sua presença, o que pode ter a justificativa de "não sou louco". As tentativas de definição dos lugares que lhe são conferidos já constituem seu reconhecimento e sua utilização. Alguém retorna duas semanas depois do primeiro encontro: "Uma pessoa da casa me disse que não adianta vir aqui; que a senhora não vai resolver nossos problemas. Eu também acho que não vai, mas...". Nessa ocasião, para ser atendido, era necessário subir uma ladeira e esperar numa fila. Todo o caminho tinha sido feito para dizer que "não adianta", dito com o qual ela concordava, mas... O mas surge no intervalo, ligando. Mas, nesse caso, aparece como uma conjunção coordenada adversativa. Conjunções coordenativas adversativas "exprimem oposição, contraste, ressalva, compensação" (Cegalla, p. 245). Nessa definição, o mas vai da oposição à compensação, coordenando. A conjunção, aqui apresentada, liga um enunciado a outro, coordenando numa adversidade, tentando articular um pensamento social institucional ao pensamento do sujeito. Nesse mas, que estamos considerando neste momento, está contido a coordenação necessária a um convívio social, apontando, porém, para uma singularidade. Nesse caso há, ainda, uma dinâmica institucional imaginária, representada pelas mães que acham algo. Para pensar, esse sujeito ocupa o lugar de mãe e diz pensar como as outras mães, todas elas parte de um mesmo cenário institucional. Mesclado a tudo isso há alguém que dá um salto, segurando-se no mas para se separar. O mas permite que se caminhe, que se espere, para dizer ante outro algo com o qual conformase plenamente, ao mesmo tempo que não tanto. ${ }^{9}$ Pode-se apostar que trazer esse enunciado ao psicanalista é buscar uma sustentação perante o Outro.

Independente do título que porta, a presença da psicanalista sustenta indagações. “... a psicanálise ultrapassa as fronteiras de um consultório bem mobiliado para descobrir que o inconsciente não está nem dentro nem fora, ele está aí onde o sujeito fala" ${ }^{10}$ (Tourinho, 1994, p. 81). Para que o sujeito fale, um encontro é criado dando novas formas ao espaço institucional. Nesse novo espaço, um campo se conforma, e o analista é colocado como objeto, dando sustentação ao sujeito que pode emergir.

9. Fink dedica algumas páginas a respeito do $n e$ francês e but inglês, enunciando o sujeito dividido, a favor e contra, consciente e inconsciente (Fink, 1995, p. 59-62). 


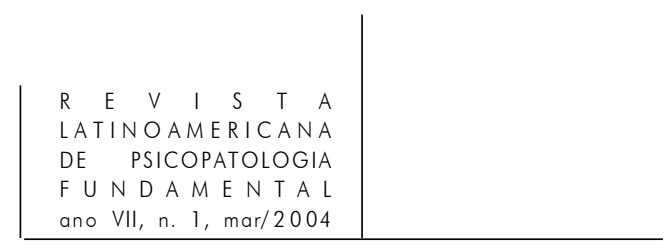

$\mathrm{Na}$ verdade, o lugar do analista é um produto comum ao analisando e ao analista que emana, que emerge, que surge, quando o paciente fala, porque é preciso que ele fale de uma certa maneira. Surge quando o paciente fala com uma certa fala e quando o analista o ouve fazendo silêncio-em-si, situando-se de uma certa maneira. Com essas duas condições, o lugar do analista se cria. (Nasio, 1999, p. 130)

Nessas novas conformações e deformações, o inesperado entra em pauta, em meio à força centrípeta do imaginário.

Essa formulação remete-me a um atendimento em duas entrevistas. $\mathrm{Na}$ primeira, um cenário, acentuadamente trágico, se desenhava. Nessa tragédia, na qual os cinco filhos e o marido alcoolizado beiravam os limites do humanamente possível, a carência dava o tom principal. A alternativa, algumas vezes diante dos filhos famintos, era dizer-lhes que comessem as paredes da casa, seu único bem. Esse bem, era agora reclamado pelo proprietário, caso não conseguisse num prazo bastante curto a quantia de dois mil reais, soma tida como impossível. Ao final dessa primeira entrevista, ficamos, as duas, mudas. Ela voltou à segunda entrevista, e a paralisia permanecia, junto a um olhar insistente. Em dado momento, perguntei: "E a casa?”. Aí outro discurso surgiu. Havia a possibilidade de pedir dinheiro a alguém e isso a aterrorizava. Ela já tinha muito, como podia querer mais?

Há sujeito em meio às pessoas. Ele aparece em seu movimento singular. A imposição de um, o tempo de outro; as tentativas de definições de cada um dos signos, socialmente tidos como claros. Esses movimentos, tradução do sofrimento e do conflito, trazem desconforto. O muito do sujeito, ilustrado no caso acima, não corresponde ao muito da pessoa.

Chegando ao campo da psicanálise, portanto, ao sujeito, não mais falamos da moral, mas da ética como possibilidade de direção.

... a experiência psicanalítica admite diversas possibilidades de clínica, desde que nesta diversidade sejam reconhecidas as condições epistemológicas e éticas para a construção do espaço psicanalítico, isto é, uma experiência centrada na fala, na escuta e regulada pelo impacto da transferência. (Birman, 1994, p. 27)

Nesse campo, a psicanalista está atenta às diferentes possibilidades de transferência desses sujeitos e à consequiente suposição pelo simbólico, permitindo a sustentação da transferência e estabelecendo a dinâmica transferencial. O lugar do analista, não facilmente, nem claramente reconhecido, é propício às suposições. Na suposição podem se presentificar o imaginário e a possibilidade. Essa possibilidade, tomada como porta de entrada, pode levar ao despontar do sujeito, tomando o desejo como direção e a demanda, como seu anúncio. Essa direção traz em seu cerne a impossibilidade, utilizando o campo psicanalítico para a produção da palavra que tenta dizer dessa impossibilidade. 


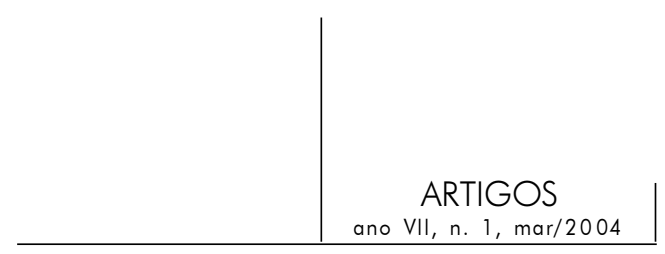

O silêncio da psicanalista pode fazer possível a escuta; o aparecimento do movimento subjetivo. Esse movimento pode ser reconhecido quando transformase num dito - que pode ser uma queixa - dando um sentido possível a esse sofrimento, por onde pode surgir uma interrogação. Essa interrogação pode ser simplesmente uma interrogação. Ou, sendo dirigida a alguém que escuta, pode ter outro efeito, outros sentidos. Um destino possível, a partir dessa escuta, é desviá-la e remetê-la ao próprio sujeito, levando-o a reconhecer-se e reconhecer seus efeitos no Outro. Em outras palavras, localizando o sujeito em relação ao seu grupo. Dessa forma, "o analista não deve ter um plano preconcebido para a sua ação; deve ficar aberto ao inesperado, deve estar pronto para deixar-se surpreender, para surpreender-se" (Nasio, 1999, p. 109).

O espaço disponibilizado pela instituição para o estabelecimento da psicanalista não garante que o campo psicanalítico se estabeleça. Algumas vezes um representante do poder na instituição faz garantir a ida a esse espaço, o que remete a uma forma de movimento da instituição diante dessa presença. Assim como "a criança está submetida ao desejo dos pais no que diz respeito à sua presença física, concreta, diante do analista" (Faria, 1998, p. 86), os habitantes dessa instituição estão a ela submetidos. Como diz Faria, este encaminhamento - o da criança - diz do desejo dos pais, no entanto, não é suficiente para dizer do desejo do filho. Continuando a analogia, leva-se em conta a existência de um funcionamento específico desta instituição, onde se consideram os sintomas de cada um dos instituintes. Os movimentos decorrentes desses encontros falam desses sintomas. Dessa forma, e continuando a referência a Faria, assim como a ida da criança ao analista não é garantia para gerar uma demanda, a aproximação ao espaço ocupado pelo psicanalista pode ser acolhido, mas não é garantia de que dali possa gerar uma demanda, enquanto pedido de análise.

\section{A transferência}

A transferência tem importância e lugar especial num tratamento psicanalítico. Acontece também fora deste, nas relações sociais.

Fora da situação da análise, o fenômeno de transferência é constante, onipresente nas relações, sejam elas profissionais, hierárquicas, amorosas etc. Nesse caso, a diferença com aquilo que ocorre em uma análise está em que os dois parceiros estão presos, cada um por seu lado, a sua própria transferência, da qual, com muita frequiência, não se tem consciência; motivo pelo qual não é organizado o lugar de intérprete, tal como o encarnado pelo analista, na situação de um tratamento analítico. (Chemama, 1995, p. 217) 


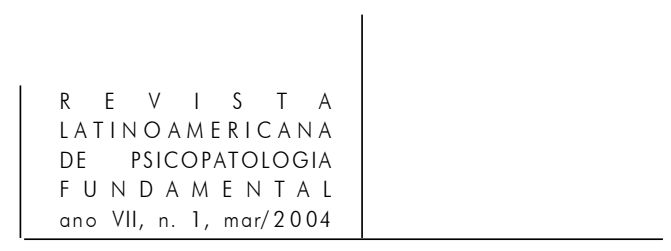

No tratamento psicanalítico, a transferência é condição - nos casos de neuroses - para que o psicanalista possa apropriar-se do ato analítico e para que o tratamento aconteça. Fora da análise é condição de socialização.

Há peculiaridades da transferência num e noutro lugar, delimitados o objeto e o campo de atuação.

Sempre, e nas diferentes formas de se considerar o outro, há uma tentativa de vínculo, ou uma tentativa de utilização desse outro, representante do Outro. Pode-se então definir a transferência como uma forma enganosa que permite a um sujeito falar de si através de e/ou para o outro. Enganosa, no sentido de que é dado ao outro sustentar a criação quando, na verdade, o que sustenta é a suposição do sujeito colocado a partir do Outro. Freud usou o termo "falsa ligação", sobre o qual diz das pacientes, especialmente mulheres, que colocavam nele desejos antes atribuídos a outros. "Desde que descobri isso, tenho podido, todas as vezes que sou pessoalmente envolvido de modo semelhante, presumir que uma transferência e uma falsa ligação tornaram a ocorrer. Curiosamente, a paciente volta a ser enganada todas as vezes que isso se repete" (Freud, 1895, p. 314).

A especificidade da transferência no tratamento psicanalítico dá-se a partir do que se faz - e aí o analista faz alguma coisa - com essa forma particular de dirigir-se ao outro (Dunker, 1994, p. 101). A partir da transferência, na psicanálise, o sujeito, além de dirigir-se ao outro, outorga a este um saber suposto sobre si, este si inconsciente. Pode-se, então, dizer que a psicanálise oferece um lugar de fala para que apareça o sujeito a partir de sua escuta. Este não é um lugar comumente encontrado socialmente.

Num atendimento psicanalítico, a forma como aparece a transferência é, portanto, um indicador de como funciona esse sujeito, e o andamento de um processo analítico permite que essa forma possa ir tomando diferentes consistências e dimensões, uma vez que o outro lado, o psicanalista, ausenta-se enquanto sujeito, possibilitando que o sujeito em questão possa aparecer. É um processo em que o sujeito experimenta, investe, recua, tateia. Avanços e recuos são sustentados pela presença do psicanalista e esta, pela aposta na substância inconsciente.

Embora a transferência não seja exclusiva do processo psicanalítico, na psicanálise utiliza-se dela para que o processo aconteça. A formalização do conceito transferência, na psicanálise, surge e se modifica em consonância com a construção do que é o tratamento psicanalítico em Freud: o que opera, como opera, por quem e para que $(\mathrm{m})$. As dificuldades encontradas por Freud na sua relação com o paciente, ou seja, a partir da transferência, fizeram-no mudar a técnica ao mesmo tempo que fizeram-no pensar numa nova forma de tratar a histeria. "Se todos os pacientes tivessem sido hipnotizáveis, não teria havido psicanálise; e, nesse sentido, pode-se sustentar que a psicanálise nasceu da resistência e dos efeitos negativos da transferência" (Lagache, 1990, p. 7). 


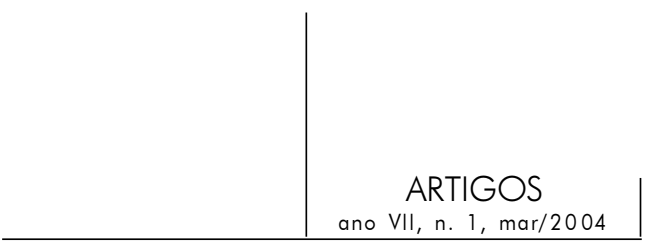

Em 1914, Freud analisa a transferência no processo psicanalítico como uma relação amorosa e artificial que contraria as normas sociais. Alerta aos psicanalistas que o amor que surge nessa relação, pela paciente, não se deve aos atributos do psicanalista em si, mas à situação analítica. Esse amor aí manifesto é uma repetição, assim como todo amor, e reproduz protótipos infantis. A forma de resposta a esse amor, pelo analista, deve ser não respondendo diretamente a ele e, ao mesmo tempo, deixando que se manifeste para que seja analisado. "É, portanto, tão desastroso para a análise que o anseio da paciente por amor seja satisfeito, quanto que seja suprimido" (Freud, 1914, p. 183). A abstinência aparece, portanto, como um importante fator a favor do tratamento. No final de sua obra, em 1938, diz que a transferência

... altera toda a situação analítica; empurra para o lado o objetivo racional que tem o paciente para ficar sadio e livre de seus achaques. Em lugar disso, surge o objetivo de agradar o analista e de conquistar o seu aplauso e amor. (...) Este (o analista) pode modestamente admitir para si próprio que se dispôs a uma empresa difícil sem suspeitar sequer dos extraordinários poderes que estariam sob seu comando. (p. 189-90)

Para Lacan, pela transferência percorre-se o caminho da análise procurando-se uma verdade a partir da palavra, mentirosa (Lacan, 1953-1954). Nesse trajeto, pretende-se saber.

Essa demanda pode vir de formas surpreendentes dentro da instituição:

"Aquele menino é muito envergonhado. Vem aqui, menino! Ele não vem não”. Várias entrevistas são feitas com esse pai, com um "menino envergonhado" sentado a uma distância em que podia ser visto e que ao mesmo tempo permitia que o pai falasse.

"Estou com uma depressão..." é dito por uma mulher que mantém os olhos nos pratos sendo lavados. Diante do meu direcionamento corporal essa fala se desdobra para "Não sei o que é...".

Querer saber "o que era" levou-a a entrevistas durante todo o tempo em que se hospedou na instituição para tratamento da filha. (Essas estadas de alguns meses tiveram intervalos de outros meses, até que a filha teve alta).

No consultório, algumas etapas se interpõem entre o surgimento da idéia de procurar ajuda e o momento de formular esse pedido diante de alguém, como: escolha do profissional, distância a ser percorrida, tempo disponível, pagamento etc., até que um telefonema possa ser feito e um agendamento possa ser realizado. Em outras palavras, o espaço tem de ser buscado. Nessa instituição, o espaço está disponível, em meio a tantos outros espaços domésticos, sem que, muitas vezes, se dê conta disso. E o campo acontece de forma muito menos premeditada por parte de quem se oferece ao tratamento ou ao início de um tratamento. Esses 


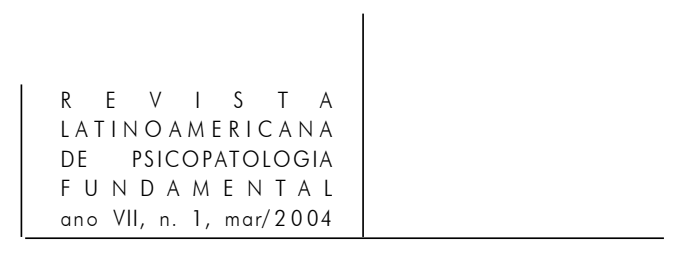

espaços podem ser confundidos até que o campo psicanalítico se estabeleça a partir do espaço ocupado por dois lugares, o de sujeito e o de objeto, em que o de sujeito é premeditadamente reservado.

Retomando a questão da pesquisa, no tratamento psicanalítico apresentase uma "incapacidade fundamental, fundadora de atender à demanda do sujeito" (Chemama, 1995, p. 220). Por essa via acontece a sustentação da transferência, visando o desejo constituinte do sujeito. Fora desse campo, a transferência continua a circular, acreditando-se, imaginariamente, que a demanda possa ser atendida e, quando não o é, atribui-se a algo como incapacidade, seja lá onde se possa colocar essa incapacidade. Na instituição esta constatação leva, freqüentemente, a reorganizações normativas ou exclusões.

\section{Considerações finais}

Sobre a instituição, a princípio talvez pudesse ser delimitada pelo espaço físico onde as pessoas se hospedam: o terreno e a construção concreta, de tijolos; seu endereço. Vai aparecendo, então, uma rede de relações que a conforma, como, por exemplo, contatos com hospitais e assistentes sociais, tanto em São Paulo como em outras cidades. Essa rede gera movimentos na instituição, como aquele que pudemos acompanhar, trazendo a psicanalista de volta para dentro da instituição, a partir da queixa de uma das mães, num dos hospitais, de que the faltava "alguém que a ouvisse". Ademais, essa instituição tem o formato de uma residência e uma dinâmica doméstica e centralizadora, propondo-se a disponibilizar o bem, o que pressupõe um mal, como seu par oposto, que evita.

Os locais para os atendimentos psicanalíticos, durante os primeiros anos, circularam entre os vários espaços da casa e a sala de atendimento. Esta, quando supostamente disponível, nem sempre realmente o estava (ainda que se supusesse sabido, de antemão, seu horário de ocupação pelo serviço de psicanálise). A chegada da psicanalista, então, causava surpresas e formas improvisadas de reorganizar o espaço.

Surpresa, nesse contexto, pode ser entendida como um corte num certo trajeto, lançando novas possibilidades; uma definição de inconsciente, um dos conceitos fundamentais para a definição do campo psicanalítico. A surpresa traz a possibilidade de que uma outra cena apareça fazendo entrecruzamento do impossível com o possível. (O possível constitui a constância da ordem institucional e seu bem; ao que ela tenta responder.) Surpresa condensa a situação da sala a ser desocupada, e/ou ocupada, do enigma da chave da sala a ser encontrada. Pode-se continuar acompanhando essa sequiência, passando pelo que 


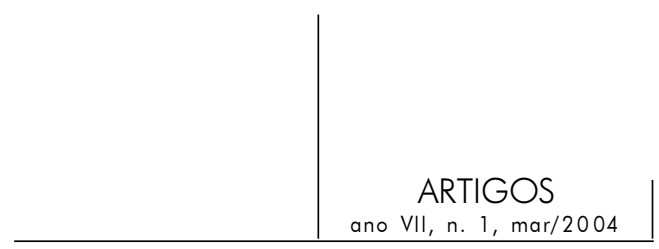

se chama aí de descontrole emocional de um dos habitantes da casa, pelo aparecimento de um relacionamento amoroso, ou pela morte de um doente. Esses fenômenos não são cogitados antes que apareçam. E por ocasião de seu aparecimento são rápida, enérgica e, o quanto se pode, silenciosamente rearranjados num esforço em trazer de volta a normalidade institucional, fazendo aparecer a possibilidade de tratamento e a cura do corpo doente e excluindo impossibilidades que essa possibilidade comporta. As impossibilidades manifestadas nesse contexto comportam desordenações de várias ordens: indo do corpo deformado àquilo que se assemelha ao que socialmente é chamado de loucura, além do mal-entendido e daquilo que nunca se satisfaz. No âmbito do possível as pessoas tentam acalmar-se, controlar-se, termos não estranhos para situar as pessoas na tentativa de responder às demandas institucionais, continuando merecedoras de seu provimento.

A instituição, normativa, pretende calar o corpo gritante, compondo um discurso sem corpo. A doença grave, com a morte como seu acompanhante próximo, tende a compor um corpo sem discurso. A presença da psicanalista permite a composição pela palavra, dando lugar a que apareçam a "depressão", a contrariedade, os limites, a vergonha, o medo; que também podem ser qualificados como os buracos do e no corpo, a dor e a incompletude.

$\mathrm{O}$ que vai sendo conformado pela presença da psicanalista tem endereço transmutante, podendo dar nova direção uma vez, ou uma sequiência de vezes. $\mathrm{O}$ destino desse trajeto pode ser interrompido pelos trajetos institucionais ou contingenciais. No entanto, encontros vão acontecendo; a partir deles laços se formam e, através desses, falas que, em alguns casos, podem ser lidas como queixa ou como pedido. A forma como a transferência é tomada e utilizada faz parte de táticas na premeditação de um tratamento. Um tratamento possível nesse contexto que consiste em desvelamentos sustentados pela transferência.

A constituição dessa nova espacialidade - a configuração do campo onde pode ser reconhecido o sujeito - dá uma possibilidade de endereçamento disso que entrelaça o possível e impossível.

\section{Referências}

Badiou, A. Teoria do sujeito. In: O ser e o evento. Rio de Janeiro: Jorge Zahar, 1988. Berlinck, M. T. Psicopatologia Fundamental. São Paulo: Escuta, 2000.

Birman, J. Psicanálise, ciência e cultura. Rio de Janeiro: Jorge Zahar, 1994.

Chemama, R. (org.) Dicionário de psicanálise. Porto Alegre: Artes Médicas, 1995.

Clavreul, J. A ordem médica: poder e impotência do discurso médico. São Paulo: Brasiliense, 1983. 


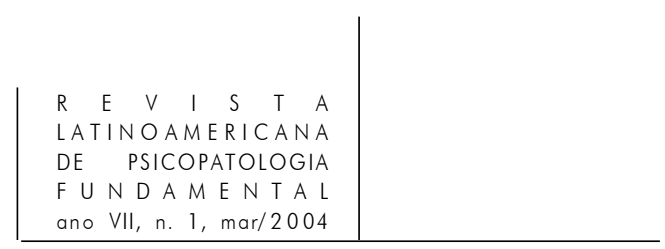

Dunker, C. Desejo, pulsão e fantasia. In: Brauer, J. F. (org.). A criança no discurso do Outro. São Paulo: Iluminuras, 1994.

FARIA, M. R. Introdução à psicanálise de crianças: o lugar dos pais. São Paulo: Hacker, 1998.

Figueiredo, L. C. Modos de subjetivação no Brasil e outros escritos. São Paulo: Escuta, 1995.

Fink, B. O sujeito lacaniano. Rio de Janeiro: Jorge Zahar, 1998.

Freud, S. Edição Standard Brasileira das Obras Psicológicas Completas - ESB. Rio de Janeiro: Imago, 1996.

(1895). Estudos sobre a histeria. In: ESB. Op. cit. v. II.

(1908). Moral sexual civilizada e doença nervosa moderna. In: ESB. Op. cit. v. IX.

(1912). Totem e tabu. In: ESB. Op. cit. v. XII.

(1914). Observações sobre o amor transferencial. In: ESB. Op. cit. v. XII.

(1915). Reflexões para os tempos de guerra e morte. In: ESB. Op. cit. v. XIV.

(1921). Psicologia de grupo e a análise do ego. In: ESB. Op. cit. v. XVIII.

(1930). O mal-estar na civilização. In: ESB. Op. cit. v. XXI.

(1938). Esboço de psicanálise. Cap. VI - a técnica da psicanálise. In: ESB. Op. cit. v. XXIII.

KAËs, R. Realidade psíquica e sofrimento nas instituições. In: A instituição e as instituições. São Paulo: Casa do Psicólogo, 1989.

Lacan, J. (1953-1954). O seminário. Livro 1. Os escritos técnicos de Freud. Rio de Janeiro: Jorge Zahar, 1996.

(1959-1960). O seminário. Livro 7. A Ética. Rio de Janeiro: Jorge Zahar, 1997.

LAGACHE, D. A transferência. São Paulo: Martins Fontes, 1990.

MinatTi, S. P. A transferência como via de reflexão para atendimento numa instituição.

Pulsional Revista de Psicanálise, São Paulo, ano XV, n. 159, p. 28-35, jul.2002.

NAsio, J.-D. Como trabalha um psicanalista? Rio de Janeiro: Jorge Zahar, 1999.

Prates, A. L. Feminilidade e experiência psicanalítica. São Paulo: Hacker, 2001.

Quinet, A. Teoria e clínica da psicose. Rio de Janeiro: Forense Universitária, 2000.

Tourinho, M. L. O que pode um analista no hospital? 1994. Dissertação (mestrado). Pontifícia Universidade Católica de São Paulo.

VALAS, P. As dimensões do gozo. Rio de Janeiro: Jorge Zahar, 2001.

Vallejo, A. Topología de J. Lacan: del narcisismo. Argentina: Helguero, 1979.

\section{Resumos}

Este texto surge de la tentativa de definir la atención de pacientes en una institución, a partir de una propuesta de trabajo psicoanalítico. El análisis de esa situación se hace por un recorte y un montaje, un recurso artificial, tomando en 


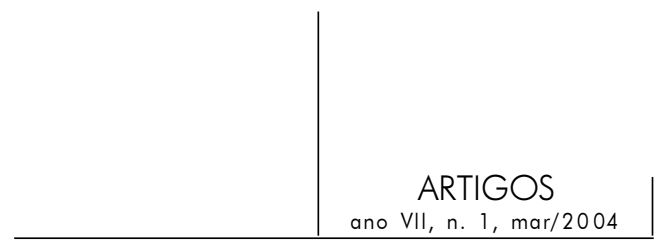

consideración el espacio institucional con su historia y finalidad como campo de acogida de sus habitantes. Como personajes centrales están estos habitantes, cuyo foco es el sujeto, distinto de persona. Como tercero elemento, la psicoanalista, cuya presencia ha posibilitado el aparecimiento del campo considerado. Del encuentro de la institución con sus componentes y la psicoanalista se va delineando una dinámica que posibilita la aparición del sujeto en medio de las personas, en las relaciones. Esta trayectoria habla de posibilidades o imposibilidades como el espacio de la persona. Habla también de las posibilidades e imposibilidades como el campo del sujeto.

Palabras clave: Psicoanálisis, institución, sujeto, transferencia

Ce texte émerge de la tentative de définir les traitements suivis au sein d'une institution, à partir de la proposition d'un travail psychanalytique. L'analyse de cette situation se fait au travers d'un découpage et d'un montage - un recours artificiel -, prenant en considération l'espace institutionnel, avec son histoire et sa finalité, comme espace d'accueil. Les personnages centraux en sont les habitants de l'institution, considérés comme sujets plutôt que personnes. Comme troisième élément, la psychanalyste, dont la présence rend possible l'émergence d'un champ, étudié ici. Dans la rencontre de l'institution et de ses composantes avec l'analyste se dessine une dynamique qui rend possible l'émergence du sujet parmi les personnes, dans leurs relations. Cette trajectoire traite de possibilités ou d'impossibilités comme champ de la personne. Elle évoque également les possibilités et les impossibilités comme champ du sujet.

Mots clés: Psychanalyse, institution, sujet, transfert

The present article is the result of an attempt to define the services provided at an institution, based on a proposal for psychoanalytic work. This situation was analyzed by the artificial resource of cutting and assembling, taking into account the institutional space and its history and purpose as a place for shelter. This institution focuses on the subject as distinct from the person, and the inhabitants play a central role there. The psychoanalyst comes in as a third element whose presence has allowed the construction of the space. In the meeting between the institution, with its participants, and the psychoanalyst, a process is set in where each subject can stand out from other persons through their relationships. This process leads to a discussion of the possibilities or impossibilities of being a person's space. The institution's history refers to the possibilities or impossibilities as the field of the person and to the possibilities and impossibilities as the field of the subject.

Key words: Psychoanalysis, institution, subject, transference

Versão inicial recebida em janeiro de 2003

Versão revisada recebida em setembro de 2003 